\title{
FONTES E NÍVEIS DE SALINIDADE NA GERMINAÇÃO DE SEMENTES DE Crotalaria juncea L.
}

\author{
Sources and levels of salinity on germination of Crotalaria juncea L. seeds
}

\author{
Anísio da Silva Nunes ${ }^{1}$, André Luís Faleiros Lourenção ${ }^{2}$, Carmen Regina Pezarico ${ }^{3}$, \\ Silvana de Paula Quintão Scalon ${ }^{4}$, Manoel Carlos Gonçalves ${ }^{5}$
}

\begin{abstract}
RESUMO
Objetivou-se avaliar o efeito dos sais cloreto de cálcio $\left(\mathrm{CaCl}_{2}\right)$, cloreto de sódio $(\mathrm{NaCl})$ e cloreto de potássio $(\mathrm{KCl})$ na germinação de Crotalaria juncea L. As sementes foram acondicionadas em caixas tipo gerbox, forradas com duas folhas de papel-filtro e umedecidas com as soluções-teste. Em cada tratamento foram utilizadas 200 sementes, dispostas em quatro repetições de 50 sementes. A indução do estresse salino foi realizada com soluções de $\mathrm{NaCl}, \mathrm{CaCl}_{2}$ e $\mathrm{KCl}$ com potenciais osmóticos de 0 ; -0,4; - 0,8 ; 1,2;-1,6 e -2,0 MPa. Foram realizadas avaliações de porcentagem de germinação, fitotoxicidade, tamanho de plântulas, matéria seca e IVG. O delineamento experimental utilizado foi o inteiramente casualizado, em esquema fatorial $(3 \times 5)+1$, composto pelas três fontes salinas em cinco doses e uma solução- teste. $\mathrm{O}$ aumento da concentração de $\mathrm{KCl}$ provocou toxicidade, prejudicando o IVG, a porcentagem de germinação e o crescimento de plântulas de $C$. juncea, enquanto as concentrações de $\mathrm{NaCl}_{\text {e }} \mathrm{CaCl}_{2}$ não interferiram significativamente na germinação das sementes e no vigor de plântulas.
\end{abstract}

Termos para indexação: Adubo verde, Crotalaria juncea, estresse, sal, vigor.

\section{ABSTRACT}

This study was carried out in order to evaluate the effect of calcium chloride $\left(\mathrm{CaCl}_{2}\right)$, sodium chloride $(\mathrm{NaCl})$, and potassium chloride $(\mathrm{KCl})$ salts on germination of Crotalaria juncea $\mathrm{L}$. seeds. The seeds were placed in gerbox boxes lined with two filter paper sheets and wet with test-solution. In each treatment, 200 seeds were used, distributed in four replicates of 50 seeds. The induction of the salt stress was done with solutions of $\mathrm{NaCl}, \mathrm{CaCl}_{2}$ and $\mathrm{KCl}$ with osmotic potential of $0,-0.4,-0.8,-1.2,-1.6$, and $-2.0 \mathrm{MPa}$. Germination percentage, phytotoxicity, seedling size, mass of dry matter, and IVG were assessed. The experimental design was completely randomized, in a $(3 \times 5)+1$ factorial structure, composed of three salt sources in five levels and a test-solution. The increasing concentration of $\mathrm{KCl}$ caused toxicity, hindering the IVG, the germination percentage. and the seedling growth of $C$. juncea, while the concentrations of $\mathrm{NaCl}$ and $\mathrm{CaCl}_{2}$ did not cause significant difference in seed germination and seedling vigor.

Index terms: Green manure, Crotalaria juncea, stress, salt, vigor.

(Recebido em 27 de março de 2008 e aprovado em 10 de outubro de 2008)

\section{INTRODUÇÃO}

A salinidade do solo, resultante de processos naturais ou do mau uso da terra, ocorre em aproximadamente $10 \%$ da superfície terrestre (MENDONÇA et al., 2007). De acordo com Chinnusamy et al. (2005), concentrações de sal maiores do que $2.600 \mathrm{mg} \mathrm{L}^{-1}$ (cerca de $4 \mathrm{dS} \mathrm{m}^{-1}$ ) podem diminuir a produtividade de muitas espécies vegetais. Ainda segundo o mesmo autor, a maioria das culturas agrícolas são altamente susceptíveis à salinidade, mesmo em solos com condutividade elétrica inferior a $4 \mathrm{dS} \mathrm{m}^{-1}$. Nesse sentido, o cultivo de espécies tolerantes apresenta-se como uma alternativa viável para o reaproveitamento de áreas marginalizadas.

Originária da Índia, a crotalária (Crotalaria juncea L.) possui alto potencial de produção de biomassa e sua utilização como adubo verde pode promover melhorias nos atributos químicos, físicos e biológicos do solo, tornandoa uma importante opção na recuperação de áreas degradadas. Entretanto, pesquisas sobre o comportamento dessa leguminosa em ambientes salinos são ainda pouco frequentes na literatura (SANTOS et al., 2001).

\footnotetext{
${ }^{1}$ Engenheiro Agrônomo, Mestre - Faculdade de Ciências Agrárias/FCA - Universidade Federal da Grande Dourados/UFGD - Rodovia Dourados Itahum, Km 12 - Cidade Universitária - Cx.P. 533 - 79804-970 - Dourados, MS - anisionunes@yahoo.com.br

2Engenheiro Agrônomo, Mestre - Faculdade de Ciências Agrárias/FCA - Universidade Federal da Grande Dourados/UFGD - Rodovia Dourados Itahum, Km 12 - Cidade Universitária - Cx.P. 533 - 79804-970 - Dourados, MS - andré_lourencao@yahoo.com.br

${ }^{3}$ Engenheira Agrônoma, Setor de Comunicação e Transferência de Tecnologias/ACE/Ant -Empresa Brasileira de Pesquisa Agropecuária/EMBRAPA CPAO - Br 163, Km 253,6 - Cx.P. 661 - 79804-970 - Dourados, MS - pezarico@cpao.embrapa.br

${ }^{4}$ Bióloga, Doutora, Professora Adjunta - Faculdade de Ciências Agrárias/FCA - Universidade Federal da Grande Dourados/UFGD - Rodovia Dourados Itahum, Km 12 - Cidade Universitária - Cx.P. 533 - 79804-970 - Dourados,MS - silvanascalon@ufgd.edu.br

${ }^{5}$ Engenheiro Agrônomo, Doutor, Professor Adjunto - Faculdade de Ciências Agrárias/FCA - Universidade da Grande Dourados/UFGD - Rodovia Dourados - Itahum, Km 12 - Cidade Universitária - Cx.P. 533 - 79804-970 - Dourados/MS - manoelgoncalves@ufgd.edu.br
} 
A crotalária é uma planta arbustiva, adaptada às condições tropicais, possui crescimento ereto e determinado, desenvolvimento inicial rápido e pode atingir até 3,5 m de altura. Na agricultura é usualmente empregada como adubo verde em reforma de canaviais e como alternativa para rotação de culturas com graníferas, sendo recomendada no controle de nematóides dos cistos e das galhas em áreas infestadas. Comercialmente, sua principal utilização é na indústria, pois produz uma fibra durável e resistente, utilizada em cordoaria, fabricação de redes de pesca, sacarias e papel (MORAES et al., 2006).

A água é o fator iniciante da germinação e está envolvida direta e indiretamente em todas as demais etapas do metabolismo germinativo. Sua participação é decisiva nas reações enzimáticas, na solubilização e transporte de metabólitos, também como reagente na digestão hidrolítica de tecidos de reserva da semente. Assim, potenciais osmóticos muito negativos inibem o potencial de germinação da grande maioria das culturas cultivadas (KRON et al., 2008; MACHADO NETO et al., 2006). Nesse sentido, o grau mínimo de umidade a ser atingido pela semente para que a germinação ocorra, depende de sua composição química e da permeabilidade do tegumento (KERBAUY, 2004).

As condições para germinação de sementes nem sempre são adequadas, principalmente em solos salinos ou sódicos, podendo afetar o processo de embebição, que é dependente do potencial hídrico da semente e do meio externo. Assim, o potencial osmótico nas células do embrião da semente deve ser menos negativo do que o potencial osmótico no solo, para que ocorra a absorção da água. Outro fator atribuído à salinidade na dificuldade de germinação de sementes é quanto à entrada de íons em quantidades tóxicas, na semente (YOKOI et al., 2002).

A salinidade pode ainda interferir na germinação de sementes por outros fatores, como o gasto de energia de reserva da semente para absorver água e posteriormente não dispor desse reservatório para outros processos, induzindo mudanças nas atividades das enzimas catalase, polifenoloxidase e peroxidase (DEBOUBA et al., 2006).

Objetivou-se, neste trabalho, avaliar o efeito de diferentes fontes e concentrações de sais, na germinação de C. juncea.

\section{MATERIAIS E MÉTODOS}

O experimento foi conduzido no laboratório da Faculdade de Ciências Agrárias da UFGD, no município de Dourados-MS, no período de 16 a 30 de maio de 2007. Antes da instalação do experimento, efetuou-se uma triagem manual para se obter sementes uniformes em tamanho e estado de conservação. Em seguida, procedeu- se à desinfecção das mesmas em solução de hipoclorito de sódio a $1 \%$, durante cinco minutos.

As sementes foram dispostas em caixas de plástico tipo gerbox, forradas internamente com duas folhas de papel de filtro autoclavadas e umedecidas com $20 \mathrm{~mL}$ das soluções-teste. As caixas foram colocadas em incubadora tipo BOD, a $20^{\circ} \mathrm{C}$.

A indução do estresse salino foi realizada com soluções de $\mathrm{NaCl}, \mathrm{CaCl}_{2}$ e $\mathrm{KCl}$ nos níveis de potencial osmótico de $0 ;-0,4 ;-0,8 ;-1,2 ;-1,6$ e -2,0 MPa, empregando a metodologia descrita por Villela et al. (1991). Para o cálculo do índice de velocidade de germinação (IVG) foram realizadas contagens diárias das sementes que apresentaram protrusão da raiz primária, considerando-se germinadas aquelas em que se observou comprimento igual ou superior a $2 \mathrm{~mm}$, até a estabilização da quantidade de sementes germinadas. Do total de sementes germinadas aos 14 dias de condução do experimento, foi realizada amostragem de cinco plântulas para avaliação de tamanho (comprimento da raiz principal à inserção da primeira folha cotiledonar). Essas plântulas foram submetidas à secagem a $60^{\circ} \mathrm{C}$ por 72 horas em estufa com circulação de ar e determinados os valores da matéria seca. Para detecção da fitotoxicidade foram fixadas notas de danos observandose diferenças de porte e aspecto do tratamento, segundo escala da EWRC (1964), em que a nota 1 representa a ausência de dano e a nota 9 a morte da plântula.

O delineamento experimental utilizado foi inteiramente casualizado (DIC), em esquema fatorial com tratamento adicional $(3 \times 5)+1$, com quatro repetições de 50 sementes. Os dados foram submetidos à análise de variância pelo teste F. Para análise dos efeitos dos sais, as médias foram comparadas pelo teste de Tukey, a 5\% de significância, enquanto os efeitos das concentrações de cada fonte salina foram avaliados com base no ajuste de equações de regressão polinomial.

\section{RESULTADOS E DISCUSSÃO}

A interação entre fontes e concentrações de sais apresentou efeito significativo sobre a germinação, o tamanho de plântulas e a toxicidade (Tabela 1). Entre as fontes salinas, observou-se que a germinação da crotalária foi mais inibida pelo $\mathrm{KCl}$, com o aumento das concentrações (Figura 1). O efeito das diferentes fontes salinas na germinação de $C$. juncea diverge da maioria dos relatos da literatura científica, em que os danos do $\mathrm{NaCl}$, em geral, superam os do $\mathrm{KCl}$, como os relatados por Morais \& Menezes (2003) na germinação de sementes de soja. Por outro lado, os efeitos encontrados na maioria das variáveis avaliadas evidenciam que o aumento da concentração dos sais, expresso pela redução do potencial osmótico, prejudica a germinação e o crescimento inicial, como também observaram Botelho \& Perez (2001) na germinação e crescimento inicial de canafístula (Peltophorum dubium Taub.). 
Tabela 1 - Valores calculados do teste F e coeficiente de variação (CV) para as variáveis porcentagem de germinação, índice de velocidade de germinação (IVG), tamanho de plântulas, massa da matéria seca e fitotoxicidade. Dourados, 2007.

\begin{tabular}{lccccc}
\hline & Germinação & IVG & Tamanho & MS & Fitotoxicidade \\
\hline Test. x Trat. & $13,14^{* *}$ & $22,69^{* *}$ & $3,64^{\mathrm{ns}}$ & $0,02^{\mathrm{ns}}$ & $86,40^{* *}$ \\
Sais & $0,64^{\mathrm{ns}}$ & $39,18^{* *}$ & $10,24^{* *}$ & $0,53^{\mathrm{ns}}$ & $204,80^{* *}$ \\
Concentrações & $2,12^{\mathrm{ns}}$ & $11,10^{* *}$ & $0,19^{\mathrm{ns}}$ & $0,43^{\mathrm{ns}}$ & $17,23^{* *}$ \\
Interação & $2,24^{* *}$ & $0,75^{\mathrm{ns}}$ & $2,68^{*}$ & $0,71^{\mathrm{ns}}$ & $11,38^{* *}$ \\
\hline CV\% & 6,1 & 11,4 & 19,69 & 11,95 & 11,11 \\
\hline
\end{tabular}

* dados significativos, a $5 \%$ de probabilidade; $* *$ dados significativos, a $1 \%$ de probabilidade; ${ }^{\text {ns }}$ não significativo.

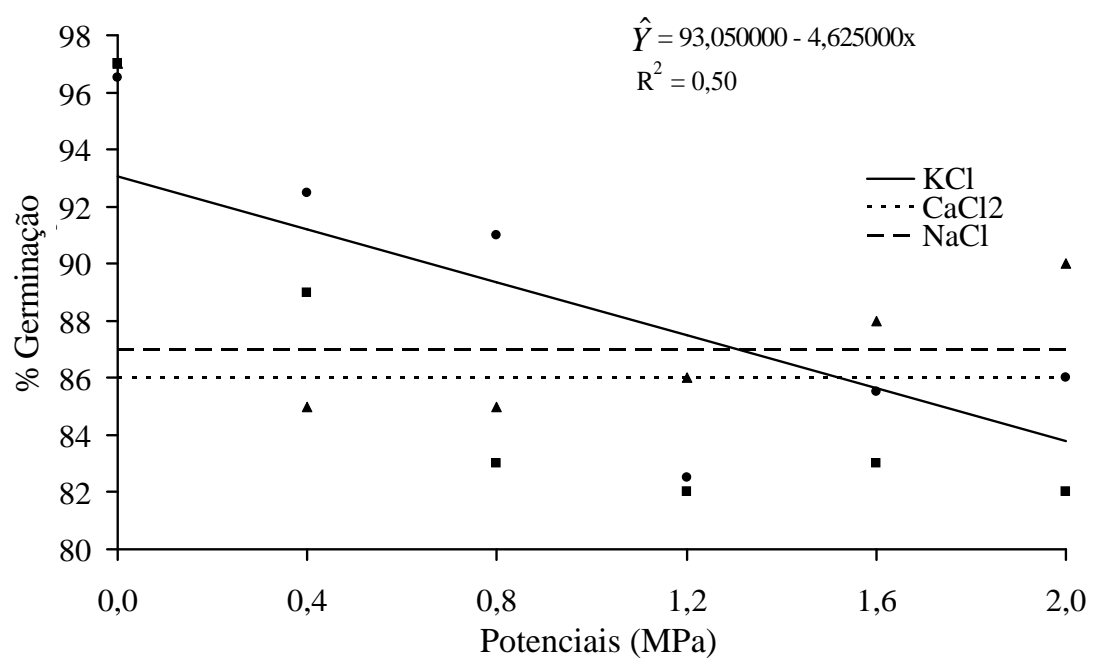

Figura 1 - Porcentagem de germinação de sementes de $C$. juncea, submetidas às diferentes fontes e níveis de salinidade.

O IVG sofreu efeitos significativos isolados dos diferentes sais e concentrações (Tabela 1). Verificou-se que o aumento na concentração salina reduziu a velocidade de germinação, ou seja, quanto mais negativo o potencial osmótico, mais lento foi o processo germinativo (Figura 2). Essa diminuição da velocidade de germinação também foi observada por Souza Filho (2000) em sementes de Leucaena leucocephala (Lam.) de Wit sob estresse salino e por Silva et al. (2007), em sementes de cevada.

A exemplo da germinação das sementes, o $\mathrm{KCl}$ também provocou decréscimo no tamanho de plântulas na medida em que os potenciais osmóticos ficaram mais negativos (Figura 3). Resultados semelhantes quanto à ação de outras fontes salinas fora apresentados por Dantas et al. (2007), em estudo sobre a germinação e crescimento inicial de sementes de feijão em condições salinas.

Não houve diferença estatística significativa para a matéria seca entre os tratamentos testados (Tabela 1). Embora Kerbauy (2004) afirme que a diminuição na absorção de água pelas sementes pode ser caracterizado por menores comprimentos de plântula e menor acúmulo de matéria seca. Azevedo Neto et al. (2004), estudando o efeito do estresse salino sobre o crescimento, resposta estomática e acúmulo de solutos em diferentes genótipos de milho, também não observaram diferenças significativas entre os genótipos testados e concluíram que a avaliação com base apenas na matéria seca pode não ser ideal para a indicação de estresses causados por ambientes salinos.

A fitotoxicidade das fontes e níveis de sais entre os tratamentos induziu efeitos diferenciados quanto ao porte e aparência das plântulas. Os maiores valores, que indicam fitotoxicidade por $\mathrm{KCl}$ e $\mathrm{NaCl}$ (Figura 4), podem ser explicados conforme Lima et al. (2001), que afirmam que os sais mais solúveis são mais nocivos e podem causar efeitos tóxicos ou mais limitantes, uma vez que as sementes ao absorverem a água, também absorvem íons que, conforme as concentrações, podem causar toxidez e ocasionar distúrbios fisiológicos e decréscimo no potencial de germinação. 


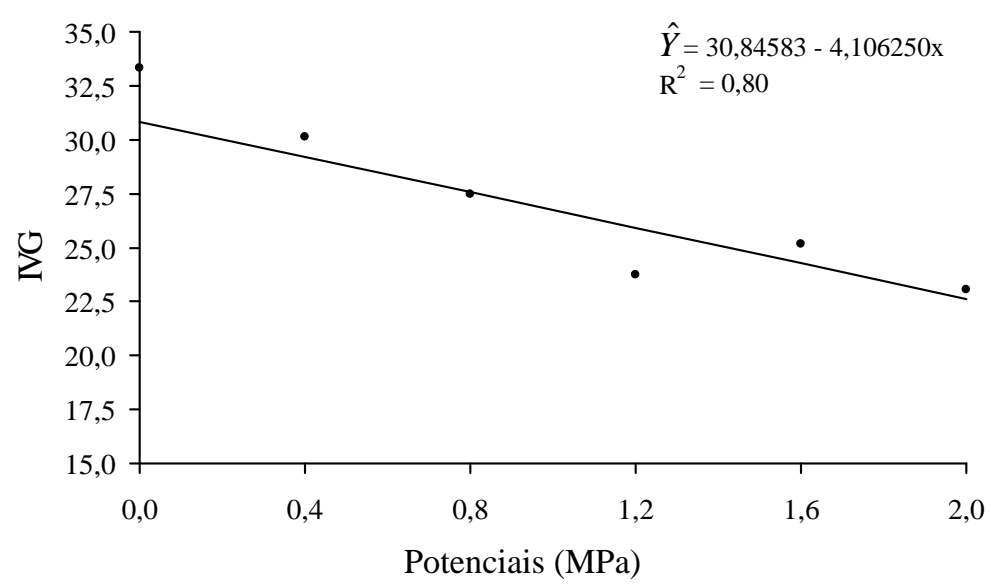

Figura 2 - Índice de velocidade de germinação (IVG) de sementes $C$. juncea, submetidas às diferentes fontes e níveis de salinidade.

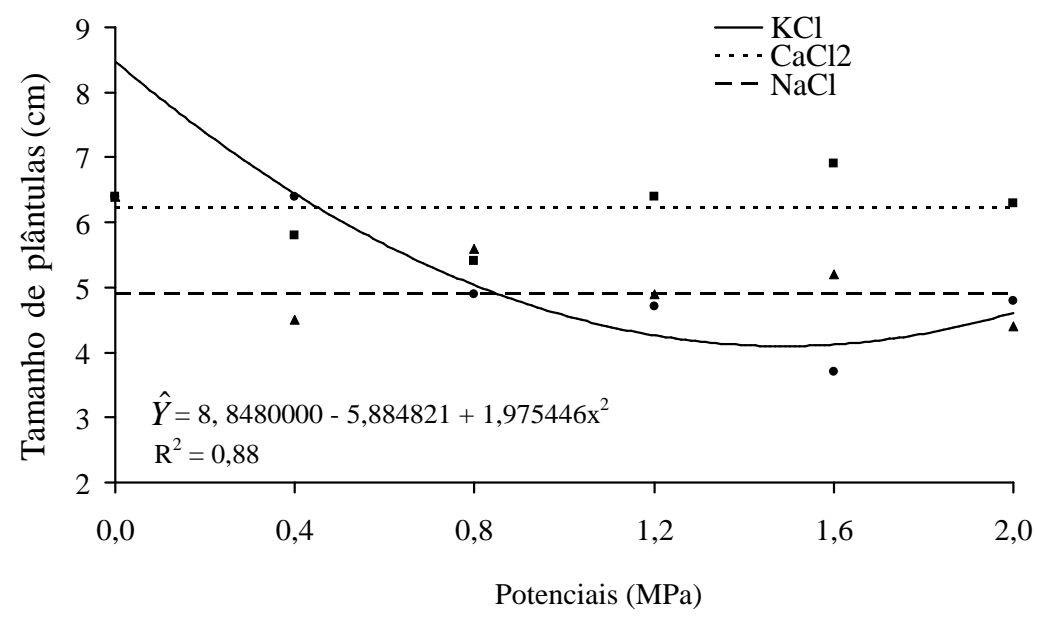

Figura 3 - Tamanho de plântulas de $C$. juncea, submetidas às diferentes fontes e níveis de salinidade, em centímetros.

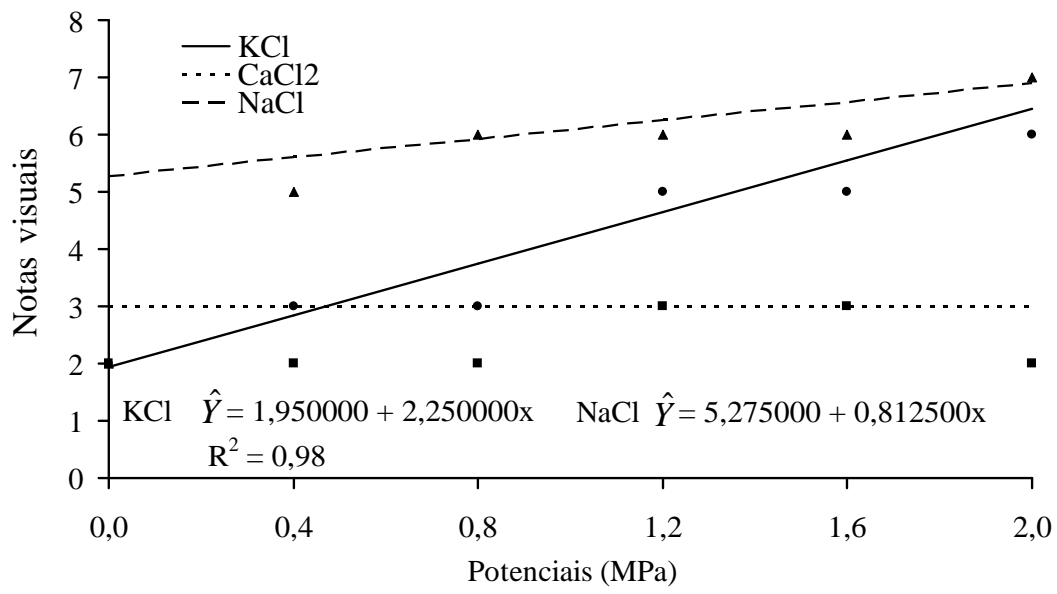

Figura 4 - Fitotoxicidade observada, em que a nota 1 representa a ausência de dano e a nota 9 a morte da plântula. 


\section{CONCLUSÕES}

Entre as fontes salinas, o $\mathrm{KCl}$, nos níveis mais altos, foi mais prejudicial à germinação das sementes e ao crescimento das plântulas de crotalária. A ordem decrescente dos efeitos nos potenciais osmóticos mais negativos foi, respectivamente: $\mathrm{KCl}, \mathrm{CaCl}_{2}$ e $\mathrm{NaCl}$ para a germinação; $\mathrm{KCl}, \mathrm{NaCl}$ e $\mathrm{CaCl}_{2}$ no crescimento inicial; e $\mathrm{NaCl}, \mathrm{KCl}$ e $\mathrm{CaCl}_{2}$ em fitotoxicidade.

\section{REFERÊNCIAS BIBLIOGRÁFICAS}

AZEVEDO NETO,A. D.; PRISCO, J. T.; ENÉAS FILHO, J.; LACERDA, C. F.; SILVA, J. V.; COSTA, P. H. A. da; GOMES FILHO, E. Effects of salt stress on plant growth, stomatal response and solute accumulation of different maize genotypes. Brazilian Journal of Plant Physiology, Pelotas, v. 16, n. 1, p. 31-38, 2004.

BOTELHO, B. A.; PEREZ, S. C. J. G. A. Estresse hídrico e reguladores de crescimento na germinação de sementes de canafístula. Scientia Agricola, Piracicaba, v. 58, n. 1, p. 43-49, 2001.

CHINNUSAMY, V.; JAGENDORF, A.; ZHU, J. K. Understanding and improving salt tolerance in plants. Crop Science, Madison, v. 45, p. 437, 2005.

DANTAS, B. F.; RIBEIRO, L. S.; ARAGÃO, C. A. Germinação, crescimento inicial e teor de proteína nos cotilédones de feijão em estresse salino. Revista Brasileira de Sementes, Pelotas, v. 29, n. 2, p. 106-110, 2007.

DEBOUBA, M.; GOUIA, H.; SUZUKI, A.; GHOEBEL, M. $\mathrm{H}$. $\mathrm{NaCl}$ stress effects on enzymes involved in nitrogen assimilation pathway in tomato "Lycopersicon esculentum" seedlings. Journal of Plant Physiology, Frankfurt, v. 163, p. 1247-1258, 2006.

EUROPEAN WEED RESEARCH COUNCIL. Report off the third and fourth meetings of the European Weed Research Council committee on methods. Weed Research, Oxford, n. 4, p. 88, 1964.

KERBAUY, G. B. Fisiologia vegetal. Rio de Janeiro: Guanabara Koogan, 2004. 452 p.

KRON, A. P.; SOUZA, G. M.; RIBEIRO, R. V. Water deficiency at different developmental stages of Glycine max can improve drought tolerance. Bragantia, Campinas, v. 67, n. 1, p. 43-49, 2008.
LIMA, K. L.; CAVALCANTE, L. F.; FEITOSA FILHO, J. C. Efeitos de fontes e níveis de salinidade da água de irrigação sobre a germinação e o crescimento da pinheira. Engenharia Agrícola, Jaboticabal, v. 21, n. 2, p. 135-144, 2001.

MACHADO NETO, N. B.; CUSTÓDIO, C. C.; COSTA, P. R. Deficiência hídrica induzida por diferentes agentes osmóticos na germinação e vigor de sementes de feijão. Revista Brasileira de Sementes, Pelotas, v. 28, n. 1, p. 142-148, 2006.

MENDONÇA, A. V. R.; CARNEIRO, J. G. A.; BARROSO, D. G. Características biométricas de mudas de Eucalyptus sp sob estresse salino. Revista Árvore, Viçosa, v. 31, n. 3, p. 365-372, 2007.

MORAES, G. A. F.; MENEZES, N. L. Desempenho de sementes de soja sob condições diferentes de potencial osmótico.

Ciência Rural, Santa Maria, v. 33, n. 2, p. 219-226, 2003.

MORAES, G. S. R.; CAMPOS, V. P.; POZZA, A. E.; FONTANETTI, A.; CARVALHO, G. J.; MAXIMINIANO, C. Influência de leguminosas no controle de fitonematóides no cultivo orgânico de alface americana e de repolho. Fitopatologia Brasileira, Brasília, v. 31, n. 2, p. 188-191, 2006.

SANTOS, R. V.; MURAOKA, T.; SOUTO, J. S.; RANGEL, A. L.; VITAL, A. F. M. Solo degradado do nordeste brasileiro: correção e absorção de nutrientes por leguminosas. In: CONGRESSO LATINO AMERICANO DA CIÊNCIA DO SOLO, 15., 2001, Varadero. Anais... Varadero: Sociedade Latino Americana da Ciência do Solo, 2001.

SILVA, R. N.; LOPES, N. F.; MORAES, D. M. Physiological quality of barley seeds submitted to saline stress. Revista Brasileira de Sementes, Pelotas, v. 29, n. 1, p. 40-44, 2007.

SOUZA FILHO, A. P. S. Influência da temperatura, luz e estresses osmótico e salino na germinação de sementes de Leucaena leucocephala. Pasturas Tropicales, Cali, v. 22, n. 2, p. 47-53, 2000.

VILLELA, F. A.; DANTAS FILHO, L.; SIQUEIRA, E. L. Tabela de potencial osmótico em função da concentração de polietileno glicol 6000 e da temperatura. Pesquisa Agropecuária Brasileira, Brasília, v. 26, n. 11, p. 1957-1968, 1991.

YOKOI, S.; BRESSAN, R. A.; HASEGAWA, P. M. Salt stress tolerance of plants. Jircas Working Report, Ishigaki, v. 1, p. 25-33, 2002. 